\title{
Expression of Autophagy-Related Proteins in Hürthle Cell Neoplasm Is Different from That in Follicular Neoplasm
}

\author{
Yoon Jin Cha, Hye Min Kim, and Ja Seung Koo \\ Department of Pathology, Yonsei University College of Medicine, Seoul, Republic of Korea \\ Correspondence should be addressed to Ja Seung Koo; kjs1976@yuhs.ac
}

Received 22 February 2017; Revised 23 June 2017; Accepted 5 July 2017; Published 27 July 2017

Academic Editor: Stamatios E. Theocharis

Copyright (C) 2017 Yoon Jin Cha et al. This is an open access article distributed under the Creative Commons Attribution License, which permits unrestricted use, distribution, and reproduction in any medium, provided the original work is properly cited.

\begin{abstract}
Purpose. We aimed to evaluate expression of autophagy-related proteins in Hürthle cell neoplasm (HCN) and follicular neoplasm (FN) and assess the clinical implications. Methods. 265 FNs (112 follicular carcinomas and 153 follicular adenomas) and 108 HCNs (27 Hürthle cell carcinomas and 81 Hürthle cell adenomas) were made into a tissue microarray. Immunohistochemical staining and Western blot for autophagy-related proteins (beclin-1, light chain (LC) 3A, LC3B, p62, and BNIP3) were performed, and the results were statistically analyzed. Results. A higher expression rate of beclin-1, LC3B, p62, and BNIP3 was found in HCN than in FN $(P<0.001)$. The expression rate of beclin-1, LC3B, p62, and BNIP3 was the highest in HCCs followed by HCAs, FCs, and FAs in that order $(P<0.001)$. HCCs were positive for the largest number of autophagy-related proteins followed by HCAs, FCs, and FAs $(P<0.001)$, and most of the positive markers identified in HCCs were the high autophagy type $(P<0.001)$, defined by positive staining for three or more of the five autophagy-related proteins. Conclusion. The autophagy-related proteins, beclin-1, LC3A, LC3B, p62, and BNIP3, were more frequently expressed in HCNs than in FNs, and HCCs showed the highest expression rate.
\end{abstract}

\section{Introduction}

Autophagy is the lysosomal disassembly of cellular components and is separated into microautophagy, chaperone-mediated autophagy, and macroautophagy subtypes. Macroautophagy is the major type of autophagy, and its underlying process has been investigated extensively. Autophagy is the process of removing and recycling dysfunctional or damaged cellular components, and it plays an important homeostatic role [1-4]. Autophagy activity is measured by the expression of several surrogate proteins involving the autophagy process: beclin-1 in nucleation [5-8], LC (light chain) 3 in elongation and generation of the autophagosome [9-11], scaffold protein $\mathrm{p} 62$ in transportation of ubiquitinated proteins to the autophagosome $[12,13]$, and BNIP3 involving mitophagy [14].

Autophagy plays a significant role in both tumor and normal cells. Cancer cells survive via angiogenesis and/or aerobic glycolysis in harsh environments including hypoxia and decreased nutrients. Highly aggressive malignant tumor cells use alternative metabolic pathways to provide energy via autophagy and to recycle cytoplasmic components in order to meet high metabolic demands $[15,16]$. However, unrestrained autophagy results in progressive consumption of cellular constituents and subsequent cellular death $[17,18]$.

Hürthle cell neoplasm $(\mathrm{HCN})$ of the thyroid is a variant of follicular neoplasm (FN). Hürthle cell adenoma (HCA) comprises $10 \%-15 \%$ of follicular adenomas (FA), and Hürthle cell carcinoma (HCC) accounts for $20 \%-25 \%$ of follicular carcinomas (FC) $[19,20]$. Hürthle cells originate from follicular epithelial cells and are characterized by ample, granular cytoplasm and prominent nucleoli [21]. In the current WHO classification, $\mathrm{HCN}$ is categorized as a variant of FN [22]. However, there is debate as to whether HCN is a disease entity distinct from FN owing to its association with nodal metastasis, higher recurrence rate and disease-related mortality $[23,24]$, and frequent TERT C228T promoter 
mutation [25]. As a result, different autophagy features are expected between $\mathrm{HCN}$ and FN based on their differing tumor biology. Autophagy in $\mathrm{HCN}$ and FN has not been evaluated to date. In the present study, we evaluated the expression of autophagy-related proteins (beclin-1, LC3A, $\mathrm{LC} 3 \mathrm{~B}, \mathrm{p} 62$, and BNIP3) in $\mathrm{HCN}$ and FN and assessed the clinical implications.

\section{Materials and Methods}

2.1. Patient Selection. Patients who underwent surgical resection and were diagnosed with $\mathrm{FN}$ and $\mathrm{HCN}$ at Severance Hospital between January 2000 and December 2013 were included. This study was approved by the Institutional Review Board of Yonsei University Severance Hospital. Patients who received preoperative chemotherapy were excluded. The histology of all resected specimens was retrospectively reviewed by a thyroid pathologist (JS Koo) with hematoxylin and eosin- (H\&E-) stained slides. Clinicopathologic data were collected from the medical records and included age at diagnosis, recurrence, metastasis, death, follow-up period, tumor size, location (right or left lobe), tumor extent (intrathyroidal or extrathyroidal), and number of metastatic lymph nodes.

2.2. Tissue Microarray. Representative areas of hematoxylineosin-stained slides and corresponding spots were marked on the surface of the matching paraffin block. Threemillimeter cores were taken from selected areas of formalinfixed, paraffin-embedded tissue (FFPE) and constructed into a $6 \times 5$ tissue microarray block. More than two tissue cores were extracted from each case, and each tissue core was assigned a unique tissue microarray location number that was linked to a database containing clinicopathologic data.

2.3. Immunohistochemistry. Antibodies used for immunohistochemistry are listed in Table 1. Sections from the TMA blocks were used for immunohistochemistry with an automatic immunohistochemistry staining device (Benchmark XT, Ventana Medical System, Tucson, AZ, USA). Briefly, $5 \mu \mathrm{m}$ thick FFPE sections were transferred onto adhesive slides and dried at $62^{\circ} \mathrm{C}$ for 30 minutes. Standard heat epitope retrieval was performed for 30 minutes in ethylene diamine tetra acetic acid, $\mathrm{pH} 8.0$, in the autostainer. The samples were then incubated with primary antibodies, followed by biotinylated anti-mouse immunoglobulins, peroxidase-labeled streptavidin (LSAB kit, DakoCytomation), and 3,30-diaminobenzidine.

2.4. Interpretation of Immunohistochemical Staining. Immunohistochemical staining was evaluated by light microscopy. The stained slides were semiquantitatively evaluated according to a previously described method [26]. Tumor cell staining was assessed as 0 , negative or weak immunostaining in $<1 \%$ of the tumor/stroma; 1 , focal expression in $1 \%-10 \%$ of the tumor; 2 , positive in $11 \%-50 \%$ of the tumor; and 3, positive in $51 \%-100 \%$ of tumor. The whole tumor area was evaluated: a score $0-1$ was considered negative and a score 2 or higher was considered positive.
TABLE 1: Source, clone, and dilution of antibodies.

\begin{tabular}{lccc}
\hline Antibody & Clone & Dilution & Company \\
\hline Beclin-1 & Polyclonal & $1: 100$ & Abcam, Cambridge, UK \\
LC3A & EP1528Y & $1: 100$ & Abcam, Cambridge, UK \\
LC3B & Polyclonal & $1: 100$ & Abcam, Cambridge, UK \\
p62 & SQSTM1 & $1: 100$ & Abcam, Cambridge, UK \\
BNIP3 & Ana40 & $1: 100$ & Abcam, Cambridge, UK \\
\hline
\end{tabular}

High autophagy status was defined as positive staining for three or more of the five autophagy-related proteins. Tumors were divided into high or low autophagy subtype, based on the autophagy status.

2.5. Protein Extraction from FFPE Tissues and Western Blot. Protein extractions from FFPE tissues were performed using a Qproteome FFPE tissue kit (Qiagen) according to the manufacturer's manual. Briefly, two or three sections from the same block were deparaffinized in xylene and rehydrated in a graded series of ethanol (100\%, $96 \%$, and $70 \%)$. The tissues were mixed with FFPE extraction buffer containing $\beta$-mercaptoethanol, incubated at $100^{\circ} \mathrm{C}$ for $20 \mathrm{~min}$, at $80^{\circ} \mathrm{C}$ for $2 \mathrm{~h}$ with agitation at $750 \mathrm{rpm}$, and then centrifuged for $15 \mathrm{~min}$ at $14,000 \times \mathrm{g}$ at $4^{\circ} \mathrm{C}$. Extracted protein content in the supernatant was determined by Bradford assay (Bio-Rad). Equal amounts of protein from each sample extract were separated on SDS-PAGE gels and blotted onto nitrocellulose membranes (Bio-Rad). Western blotting was performed with primary antibodies against beclin-1. LC3A, LC3B, p62, BNIP3, and GAPDH (Abcam) and specific bands were detected using an ECL kit (GE Healthcare Life Sciences).

2.6. Statistical Analysis. Statistical analyses were performed using SPSS for Windows, Version 23.0 (SPSS Inc., Chicago, IL, USA). Student's $t$-test was used for continuous variables. Chi-square and Fisher's exact tests were used for categorical variables. Statistical significance was set at $P<0.05$. Kaplan-Meier survival curves and log-rank statistics were employed to evaluate time to tumor recurrence and overall survival. Multivariate regression analysis was performed using the Cox proportional hazards model.

\section{Results}

3.1. Baseline Characteristics of Follicular Neoplasms and Hürthle Cell Neoplasms. There were 265 FNs comprised of 153 FAs and 112 FCs (99 minimally invasive types and 13 widely invasive types), and $108 \mathrm{HCNs}$ comprised of $81 \mathrm{HCAs}$ and 27 HCCs. Clinicopathologic features of FNs and HCNs are shown in Supplementary Tables 1 and 2 available online at https://doi.org/10.1155/2017/1372387, respectively.

3.2. Expression of Autophagy-Related Proteins in Follicular Neoplasms and Hürthle Cell Neoplasms. Expression of 


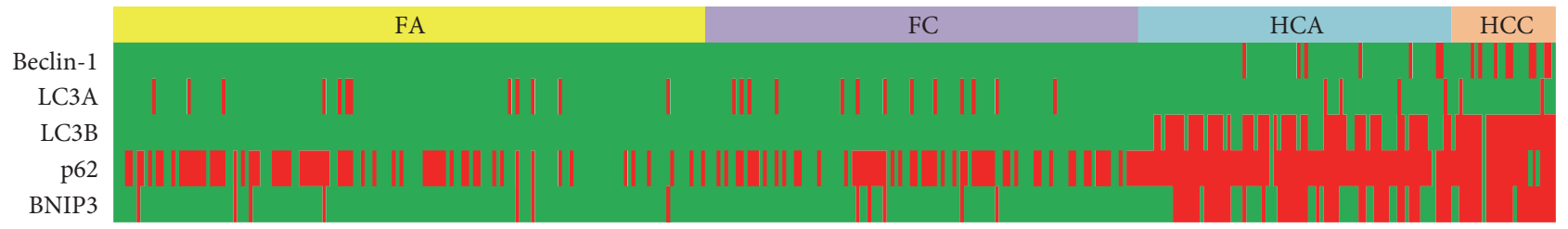

FIgURE 1: Heat map showing the expression of autophagy-related proteins in follicular neoplasms and Hürthle cell neoplasms. FA: follicular adenoma; FC: follicular carcinoma; HCA: Hürthle cell adenoma; HCC: Hürthle cell carcinoma; green: negative; red: positive.

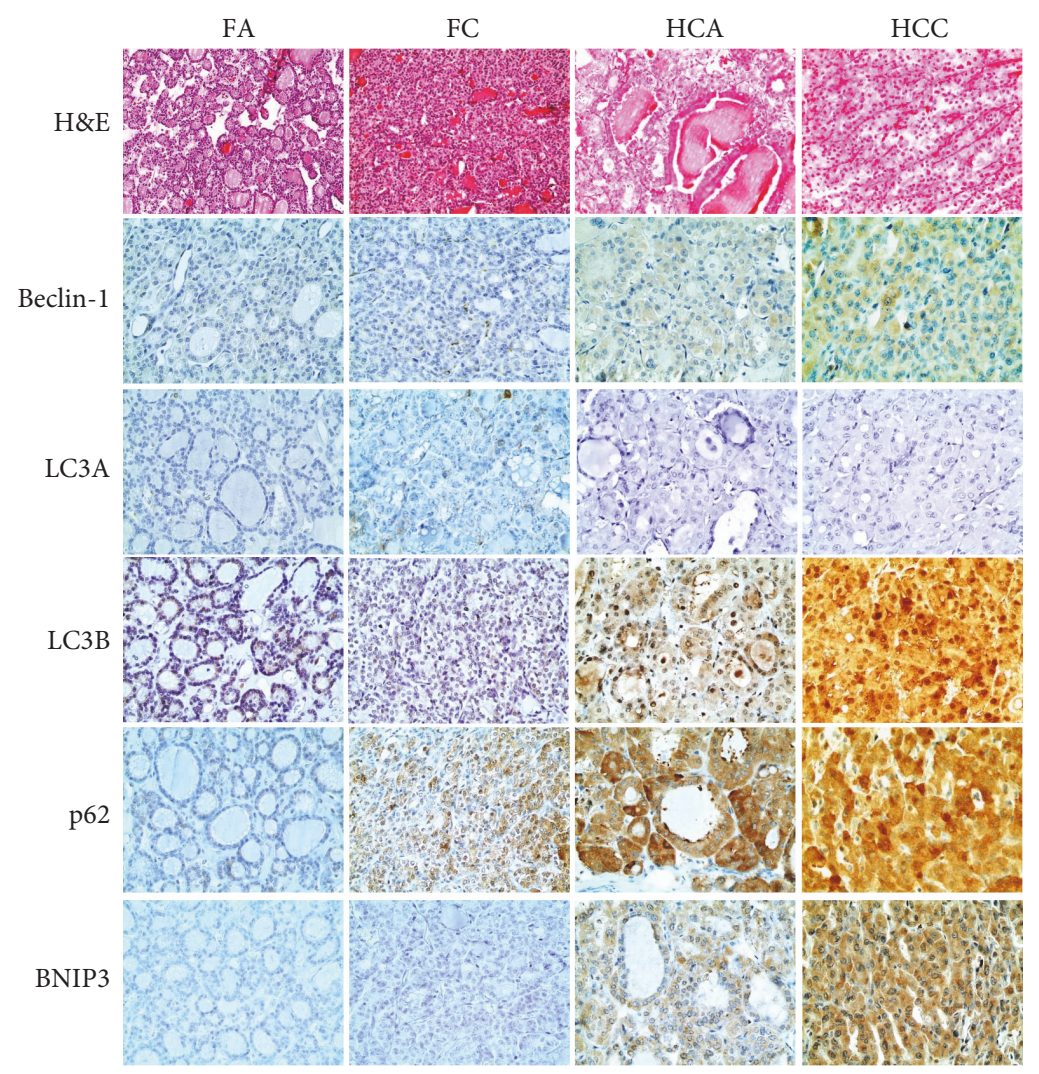

FIGURE 2: Expression of autophagy-related proteins in follicular adenoma, follicular carcinoma, Hürthle cell adenoma (HCA), and Hürthle cell carcinoma (HCC). Beclin-1, LC3B, p62, and BNIP3 are more highly expressed in Hürthle cell neoplasms than in follicular neoplasms and in HCCs than in HCAs.

autophagy-related proteins in FNs and $\mathrm{HNs}$ is shown in Figures 1 and 2. Expression of beclin-1, LC3B, p62, and BNIP3 was significantly higher in HCNs than in FNs $(P<0.001$, Table 2). Expression of beclin-1, LC3B, and BNIP3 was highest in HCCs, followed by HCAs, FCs, and FAs $(P<0.001$, Table 3$)$. HCCs showed the highest positivity rate for autophagy-related proteins followed by HCAs, FCs, and FAs $(P<0.001)$. The frequency of high autophagy type (positive for three or more autophagyrelated proteins) was highest in HCCs, followed by HCAs, FCs, and FAs $(P<0.001$, Table 4 , Figure 3$)$.

Western blot analysis for autophagy-related proteins in $\mathrm{HCC}$ and FC revealed a higher expression of beclin-1, LC3A, LC3B, and p62 in HCC than in FC (Figure 4).
3.3. Correlation between the Expression of AutophagyRelated Proteins and Clinicopathologic Factors in Hürthle Cell Carcinomas and Follicular Carcinomas. There was no significant association between the expression of autophagy-related proteins and clinicopathologic factors in HCCs. In FCs, capsular invasion was associated with BNIP3 negativity $(P=0.014)$, low number of positive markers $(P=0.013)$, and low autophagy status $(P=0.041)$, and larger tumors $(>4.0 \mathrm{~cm})$ were associated with high autophagy status $(P=0.012$ and Figure 5$)$.

3.4. The Impact of Autophagy-Related Protein Expression on Prognosis. Expression of autophagy-related proteins had no significant effect on prognosis of FCs and HCCs (Table 5). 
TABLE 2: Expression of autophagy-related proteins in follicular neoplasms and Hürthle cell neoplasms.

\begin{tabular}{|c|c|c|c|c|}
\hline Parameters & $\begin{array}{c}\text { Total } \\
N=373(\%)\end{array}$ & $\begin{array}{l}\text { Follicular neoplasm } \\
\quad N=265(\%)\end{array}$ & $\begin{array}{l}\text { Hürthle cell neoplasm } \\
\qquad N=108(\%)\end{array}$ & $P$ value \\
\hline Beclin-1 & & & & $<0.001$ \\
\hline Negative & 357 (95.7) & $265(100.0)$ & $92(85.2)$ & \\
\hline Positive & $16(4.3)$ & $0(0.0)$ & $16(14.8)$ & \\
\hline LC3A & & & & 0.218 \\
\hline Negative & $342(91.7)$ & $240(90.6)$ & $102(94.4)$ & \\
\hline Positive & $31(8.3)$ & $25(9.4)$ & $6(5.6)$ & \\
\hline LC3B & & & & $<0.001$ \\
\hline Negative & $298(79.9)$ & $265(100.0)$ & $33(30.6)$ & \\
\hline Positive & $75(20.1)$ & $0(0.0)$ & $75(69.4)$ & \\
\hline p62 & & & & $<0.001$ \\
\hline Negative & $143(38.3)$ & $138(52.1)$ & $5(4.6)$ & \\
\hline Positive & $230(61.7)$ & $127(47.9)$ & $103(95.4)$ & \\
\hline BNIP3 & & & & $<0.001$ \\
\hline Negative & $294(78.8)$ & $253(95.5)$ & $41(38.0)$ & \\
\hline Positive & $79(21.2)$ & $12(4.5)$ & $67(62.0)$ & \\
\hline
\end{tabular}

TABLE 3: Expression of autophagy-related proteins in follicular adenomas, follicular carcinomas, Hürthle cell adenomas, and Hürthle cell carcinomas.

\begin{tabular}{|c|c|c|c|c|c|}
\hline \multirow{2}{*}{ Parameters } & \multicolumn{2}{|c|}{$\begin{array}{l}\text { Follicular neoplasm } \\
\qquad N=265(\%)\end{array}$} & \multicolumn{2}{|c|}{$\begin{array}{l}\text { Hürthle cell neoplasm } \\
\qquad N=108(\%)\end{array}$} & \multirow{2}{*}{$P$ value } \\
\hline & $\begin{array}{c}\text { FA } \\
N=153(\%)\end{array}$ & $\begin{array}{c}\mathrm{FC} \\
N=112(\%)\end{array}$ & $\begin{array}{c}\text { HCA } \\
N=81(\%)\end{array}$ & $\begin{array}{c}\mathrm{HCC} \\
N=27(\%)\end{array}$ & \\
\hline Beclin-1 & & & & & $<0.001$ \\
\hline Negative & $153(100.0)$ & $112(100.0)$ & $74(91.4)$ & $18(66.7)$ & \\
\hline Positive & $0(0.0)$ & $0(0.0)$ & $7(8.6)$ & $9(33.3)$ & \\
\hline LC3A & & & & & 0.411 \\
\hline Negative & $141(92.2)$ & $99(88.4)$ & 77 (95.1) & $25(92.6)$ & \\
\hline Positive & $12(7.8)$ & $13(11.6)$ & $4(4.9)$ & $2(7.4)$ & \\
\hline LC3B & & & & & $<0.001$ \\
\hline Negative & $153(100.0)$ & $112(100.0)$ & $31(38.1)$ & $2(7.4)$ & \\
\hline Positive & $0(0.0)$ & $0(0.0)$ & $50(61.7)$ & $25(92.6)$ & \\
\hline p62 & & & & & $<0.001$ \\
\hline Negative & 85 (55.6) & $53(47.3)$ & $2(2.5)$ & $3(11.1)$ & \\
\hline Positive & $68(44.4)$ & $59(52.7)$ & $79(97.5)$ & $24(88.9)$ & \\
\hline BNIP3 & & & & & $<0.001$ \\
\hline Negative & $146(95.4)$ & $107(95.5)$ & $37(45.7)$ & $4(14.8)$ & \\
\hline Positive & $7(4.6)$ & $5(4.5)$ & $44(54.3)$ & $23(85.2)$ & \\
\hline
\end{tabular}

FA: follicular adenoma; FC: follicular carcinoma; HCA: Hürthle cell adenoma; HCC: Hürthle cell carcinoma.

TABLE 4: Number of positive autophagy markers in follicular neoplasms and Hürthle cell neoplasms.

\begin{tabular}{|c|c|c|c|c|c|c|}
\hline $\begin{array}{l}\text { Number of positive } \\
\text { markers for autophagy }\end{array}$ & $\begin{array}{c}\text { Total } \\
N=373(\%)\end{array}$ & $\begin{array}{c}\text { FA } \\
N=153(\%)\end{array}$ & $\begin{array}{c}\mathrm{FC} \\
N=112(\%)\end{array}$ & $\begin{array}{c}\text { HCA } \\
N=81(\%)\end{array}$ & $\begin{array}{c}\mathrm{HCC} \\
N=27(\%)\end{array}$ & $P$ value \\
\hline 0 & $133(35.7)$ & $81(52.9)$ & $49(43.8)$ & $2(2.5)$ & $1(3.7)$ & $<0.001$ \\
\hline 1 & $131(35.1)$ & $59(38.6)$ & $52(46.4)$ & $19(23.5)$ & $1(3.7)$ & \\
\hline 2 & 43 (11.5) & $10(6.5)$ & $8(7.1)$ & $22(27.2)$ & $3(11.1)$ & \\
\hline 3 & 49 (13.1) & $3(2.0)$ & $3(2.7)$ & $31(38.3)$ & $12(44.4)$ & \\
\hline 4 & $17(4.6)$ & $0(0.0)$ & $0(0.0)$ & $7(8.6)$ & $10(37.0)$ & \\
\hline
\end{tabular}

FA: follicular adenoma; FC: follicular carcinoma; HCA: Hürthle cell adenoma; HCC: Hürthle cell carcinoma. 


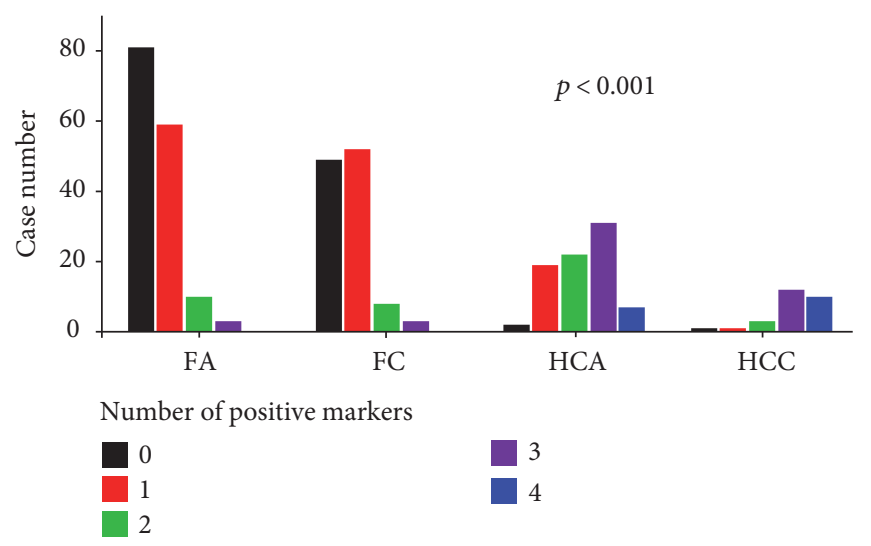

(a)

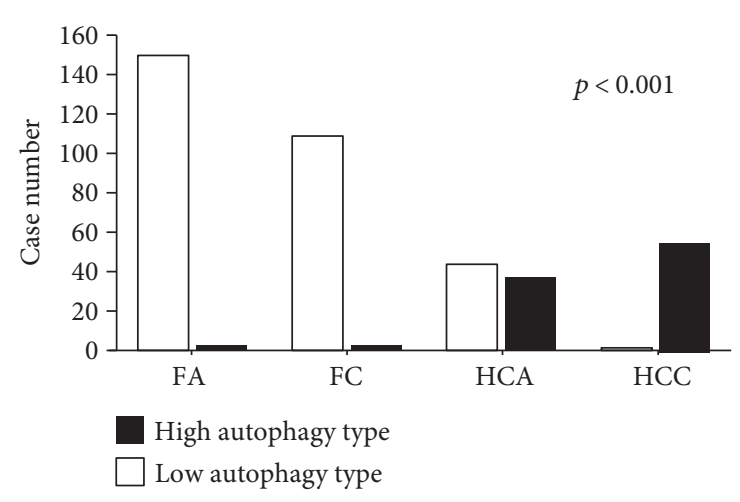

(b)

FIGURE 3: Number of positive autophagy-related proteins (a) and autophagy status (b) in follicular adenoma (FA), follicular carcinoma (FC), Hürthle cell adenoma (HCA), and Hürthle cell carcinoma (HCC). Positivity for various markers and high autophagy type are most frequently found in HCCs followed by HCAs, FCs, and FAs.
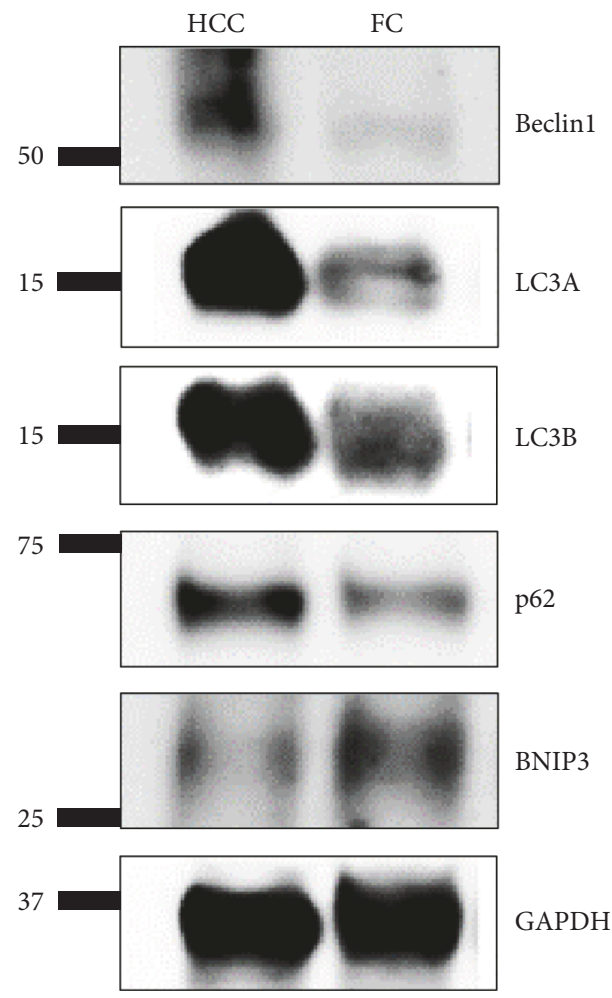

FIGURE 4: Western blot analysis for expression of autophagy-related proteins in follicular carcinoma (FC) and Hürthle cell carcinoma (HCC). Beclin-1, LC3A, LC3B, and p62 are more highly expressed in HCC than in FC.

\section{Discussion}

We evaluated the expression of autophagy-related proteins in FNs and HCNs and observed that every autophagy-related protein was more highly expressed in HCNs than in FNs. Hürthle cells have an abnormally large number of mitochondria, which results in abundant acidophilic, granular cytoplasm. A previous study showed that XTC.UC1, a cell line derived from a Hürthle cell tumor, had increased autophagosome formation, which is consistent with the findings of the present study [27]. Biologically, Hürthle cells are less active than normal follicular epithelial cells [28], and increased autophagy activity appears to be linked to cellular functions of the Hürthle cell. Increased autophagy promotes degradation of ciliary proteins and reduces ciliogenesis [29]. These phenomena have been observed in Hürthle cells in lymphocytic thyroiditis, Hürthle cell carcinoma, and Hürthle cell variant papillary thyroid carcinoma [29]. Thus, regardless of the type of thyroid disease, Hürthle cells have increased autophagy activity, fewer ciliated cells, and shorter cilia. In this study, FCs and HCCs showed significantly higher expression of autophagy-related proteins compared to FAs and HCAs, which suggests higher autophagy activity in malignant tumors than in their benign counterparts. Expression of autophagy-related proteins is reportedly related to malignant progression in various tumors [30, 31], which is consistent with findings of the present study.

BNIP3, which is one of the mitophagy-related proteins, was more highly expressed in HCNs, as described in a previous study that showed activation of mitophagy in Hürthle cells. Mitophagy activation in Hürthle cells has been found to be ineffective [27], and abnormal mitochondria accumulate as a result of reduced turnover due to defective mitophagy caused by a PARK2 gene mutation. We also found higher expression of BNIP3 in HCNs, but mitophagy itself may potentially be defective and further study is required.

One of the limitations of our study was that we used immunohistochemistry as an indicator of autophagy activity, which is a static method that may not be accurate since autophagy is more likely to be a multistep dynamic process. Since LC3A and LC3B are components of the autophagosome, expression of LC3A and LC3B could be interpreted as increased autophagy activation. However, 

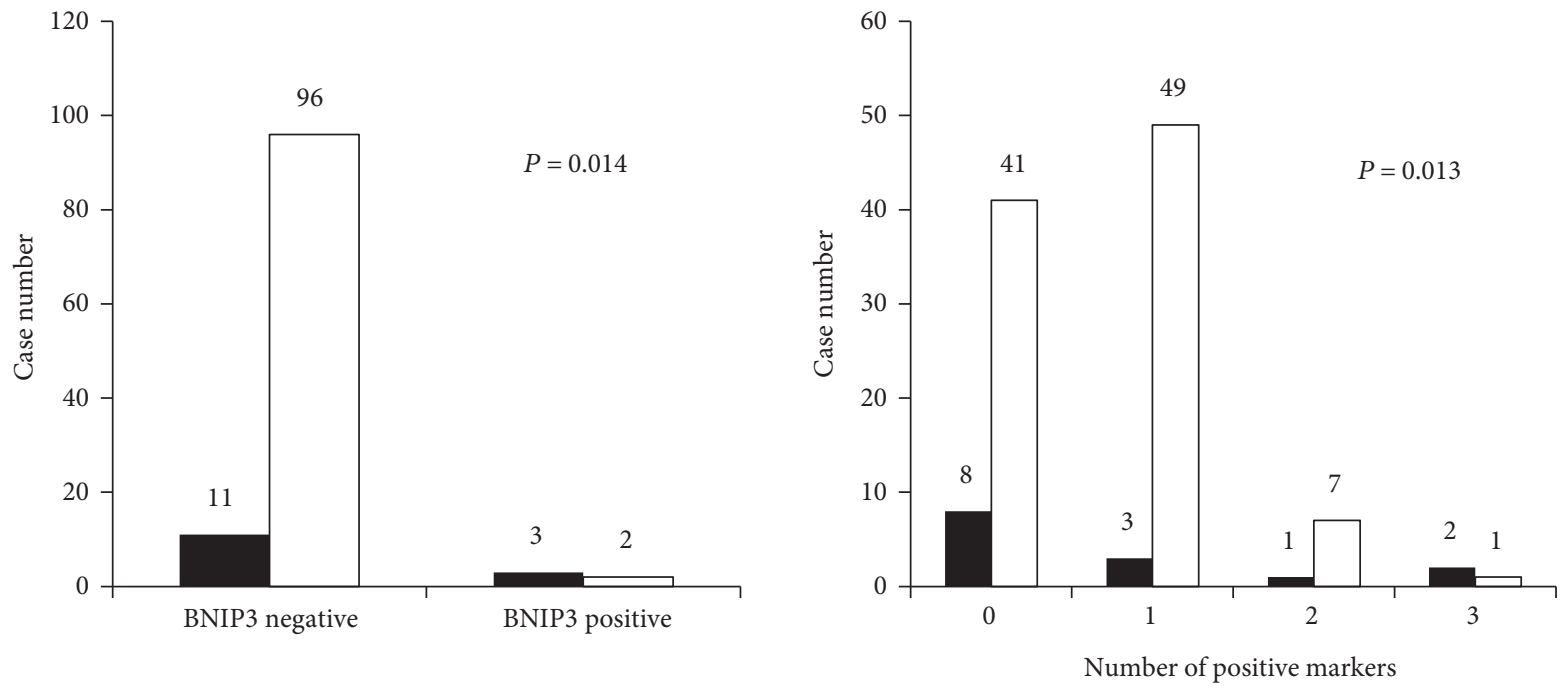

No capsular invasion

No capsular invasion

Capsular invasion

Capsular invasion
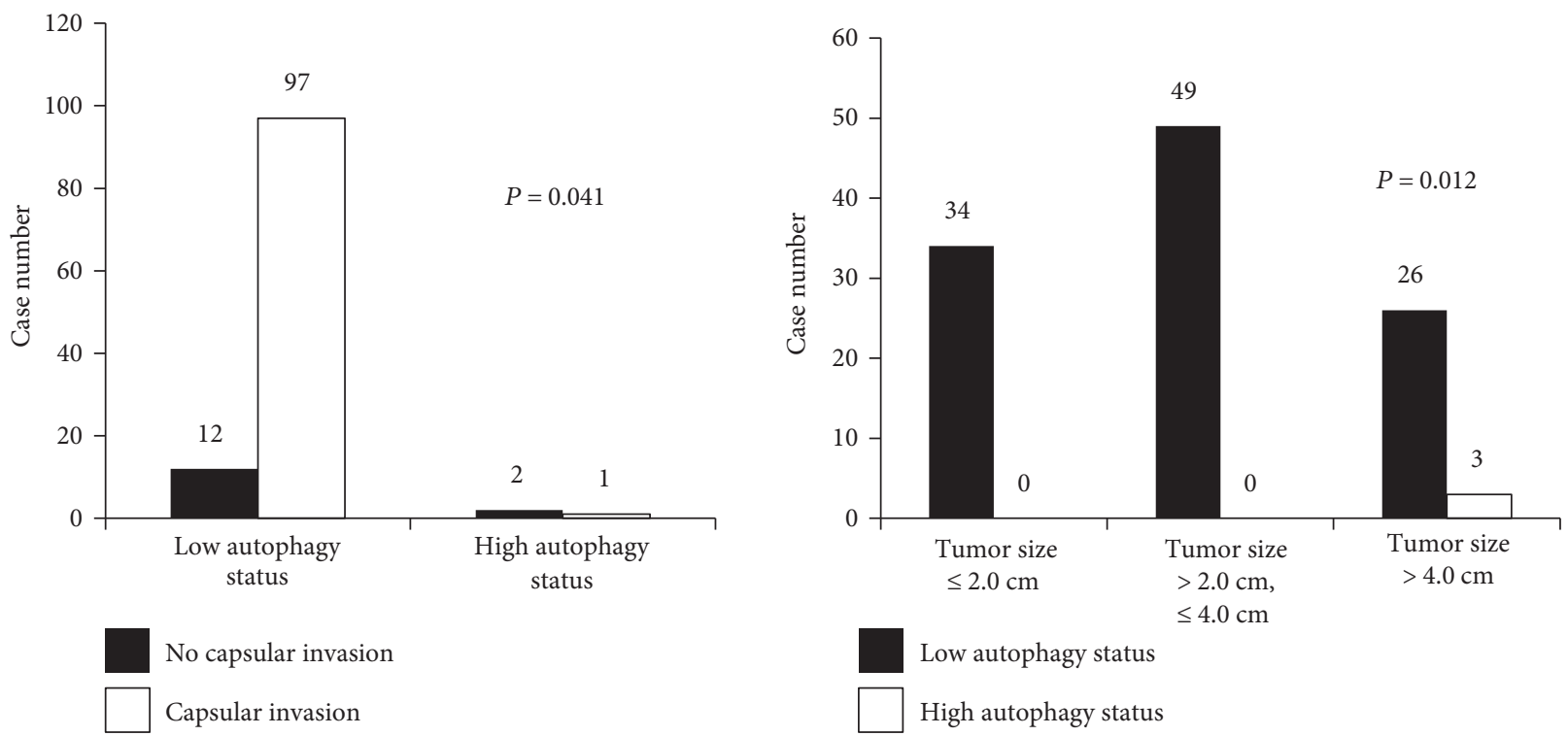

FIgURE 5: Correlation between the expression of autophagy-related proteins and clinicopathologic factors in follicular carcinoma.

an increased number of autophagosomes can be derived from delayed degradation, as well as under situations of increased autophagy activity. Therefore, monitoring of cellular autophagy flux at different time points is the most accurate for measuring autophagy activity [13]. However, we used paraffin blocks of tumor tissue and could not evaluate autophagy flux.

The other limitation of the present study is negative correlation between capsular invasion and expression of autophagy-related proteins in FC, which were partly incompatible with previous study and our conclusion that malignant tumor had higher autophagy activity. In the present study, HCC had overtly higher autophagy status than HCA and other FNs. Regarding FN, FC showed higher expression rate of autophagy-related proteins than FA, but most of
FN encompassing FC and FA belonged to low autophagy status. Thus, it appears that autophagy-related proteins might not play an important role in tumor aggressiveness in FC compared to HCC. As seen in different distributions of recognized somatic mutations between FC and HCC, tumor aggressiveness like capsular invasion might be more dependent to factors other than autophagy-related proteins in FC [21].

Autophagy markers appear to be potential therapeutic targets in cancer therapy. Autophagy inhibition has been reported to suppress tumor growth in various tumors [32-35], and HCCs could be a target for autophagy inhibition considering its high expression of autophagy markers. In conclusion, expression of autophagy-related proteins (beclin-1, LC3B, p62, and BNIP3) was higher in HCNs 
TABLE 5: Univariate analysis of the influences of autophagy-related protein expression on disease-free and overall survival among patients with follicular carcinoma and Hürthle cell carcinoma (log-rank test).

\begin{tabular}{|c|c|c|c|c|c|}
\hline Parameters & $\begin{array}{l}\text { Number of patients/ } \\
\text { recurrence/death }\end{array}$ & $\begin{array}{c}\text { Disease-free survival } \\
\text { Mean survival (95\% CI) (months) }\end{array}$ & $P$ value & $\begin{array}{c}\text { Overall survival } \\
\text { Mean survival (95\% CI) (months) }\end{array}$ & $P$ value \\
\hline Beclin-1 & & & $\mathrm{n} / \mathrm{a}$ & & $\mathrm{n} / \mathrm{a}$ \\
\hline Negative & $130 / 11 / 5$ & $\mathrm{n} / \mathrm{a}$ & & $\mathrm{n} / \mathrm{a}$ & \\
\hline Positive & $9 / 0 / 0$ & $\mathrm{n} / \mathrm{a}$ & & $\mathrm{n} / \mathrm{a}$ & \\
\hline LC3A & & & 0.942 & & 0.359 \\
\hline Negative & $124 / 10 / 4$ & $115(109-121)$ & & $120(115-126)$ & \\
\hline Positive & $15 / 1 / 1$ & $97(81-112)$ & & $97(81-112)$ & \\
\hline LC3B & & & $\mathrm{n} / \mathrm{a}$ & & $\mathrm{n} / \mathrm{a}$ \\
\hline Negative & $114 / 11 / 5$ & $\mathrm{n} / \mathrm{a}$ & & $\mathrm{n} / \mathrm{a}$ & \\
\hline Positive & $25 / 0 / 0$ & $\mathrm{n} / \mathrm{a}$ & & $\mathrm{n} / \mathrm{a}$ & \\
\hline p62 & & & 0.104 & & 0.406 \\
\hline Negative & $56 / 7 / 3$ & $88(79-96)$ & & 95 (89-101) & \\
\hline Positive & $83 / 4 / 2$ & $119(113-125)$ & & $121(113-128)$ & \\
\hline BNIP3 & & & $\mathrm{n} / \mathrm{a}$ & & $\mathrm{n} / \mathrm{a}$ \\
\hline Negative & $111 / 11 / 5$ & $\mathrm{n} / \mathrm{a}$ & & $\mathrm{n} / \mathrm{a}$ & \\
\hline Positive & $28 / 0 / 0$ & $\mathrm{n} / \mathrm{a}$ & & $\mathrm{n} / \mathrm{a}$ & \\
\hline
\end{tabular}

CI: confidence interval; $\mathrm{n} / \mathrm{a}$ : not applicable.

and HCCs compared to FNs and HCAs, respectively, and this could have implications in cancer therapeutics.

\section{Conflicts of Interest}

The authors declare that they have no conflicts of interest.

\section{Acknowledgments}

This study was supported by a grant from the National R\&D Program for Cancer Control, Ministry of Health \& Welfare, Republic of Korea (1420080). This research was supported by Basic Science Research Program through the National Research Foundation of Korea (NRF) funded by the Ministry of Science, ICT and Future Planning (2015R1A1A1A05001209).

\section{References}

[1] B. Levine and D. J. Klionsky, "Development by self-digestion: molecular mechanisms and biological functions of autophagy," Developmental Cell, vol. 6, no. 4, pp. 463-477, 2004.

[2] N. Mizushima, "Autophagy: process and function," Genes \& Development, vol. 21, no. 22, pp. 2861-2873, 2007.

[3] N. Mizushima, B. Levine, A. M. Cuervo, and D. J. Klionsky, "Autophagy fights disease through cellular self-digestion," Nature, vol. 451, no. 7182, pp. 1069-1075, 2008.

[4] Z. Yang and D. J. Klionsky, "Eaten alive: a history of macroautophagy," Nature Cell Biology, vol. 12, no. 9, pp. 814-822, 2010.

[5] Y. Chen, Y. Lu, C. Lu, and L. Zhang, "Beclin-1 expression is a predictor of clinical outcome in patients with esophageal squamous cell carcinoma and correlated to hypoxia-inducible factor (HIF)- $1 \alpha$ expression," Pathology Oncology Research, vol. 15, no. 3, pp. 487-493, 2009.
[6] B. X. Li, C. Y. Li, R. Q. Peng et al., "The expression of beclin 1 is associated with favorable prognosis in stage IIIB colon cancers," Autophagy, vol. 5, no. 3, pp. 303-306, 2009.

[7] L. Pirtoli, G. Cevenini, P. Tini et al., "The prognostic role of beclin 1 protein expression in high-grade gliomas," Autophagy, vol. 5, no. 7, pp. 930-936, 2009.

[8] X. B. Wan, X. J. Fan, M. Y. Chen et al., "Elevated beclin 1 expression is correlated with HIF-1alpha in predicting poor prognosis of nasopharyngeal carcinoma," Autophagy, vol. 6, no. 3, pp. 395-404, 2010.

[9] Y. Kabeya, N. Mizushima, T. Ueno et al., "LC3, a mammalian homologue of yeast Apg8p, is localized in autophagosome membranes after processing," The EMBO Journal, vol. 19, no. 21, pp. 5720-5728, 2000.

[10] E. Sivridis, M. I. Koukourakis, C. E. Zois et al., "LC3A-positive light microscopy detected patterns of autophagy and prognosis in operable breast carcinomas," The American Journal of Pathology, vol. 176, no. 5, pp. 2477-2489, 2010.

[11] A. Yoshioka, H. Miyata, Y. Doki et al., "LC3, an autophagosome marker, is highly expressed in gastrointestinal cancers," International Journal of Oncology, vol. 33, no. 3, pp. 461-468, 2008.

[12] M. Komatsu, S. Waguri, M. Koike et al., "Homeostatic levels of p62 control cytoplasmic inclusion body formation in autophagy-deficient mice," Cell, vol. 131, no. 6, pp. 11491163, 2007.

[13] N. Mizushima, T. Yoshimori, and B. Levine, "Methods in mammalian autophagy research," Cell, vol. 140, no. 3, pp. 313-326, 2010.

[14] T. Zhang, L. Xue, L. Li et al., "BNIP3 protein suppresses PINK1 kinase proteolytic cleavage to promote mitophagy," The Journal of Biological Chemistry, vol. 291, no. 41, pp. 2161621629, 2016.

[15] K. Degenhardt, R. Mathew, B. Beaudoin et al., "Autophagy promotes tumor cell survival and restricts necrosis, 
inflammation, and tumorigenesis," Cancer Cell, vol. 10, no. 1, pp. 51-64, 2006.

[16] S. Roy and J. Debnath, "Autophagy and tumorigenesis," Seminars in Immunopathology, vol. 32, no. 4, pp. 383-396, 2010.

[17] E. H. Baehrecke, "Autophagy: dual roles in life and death?" Nature Reviews. Molecular Cell Biology, vol. 6, no. 6, pp. 505-510, 2005.

[18] J. Debnath, E. H. Baehrecke, and G. Kroemer, "Does autophagy contribute to cell death?" Autophagy, vol. 1, no. 2, pp. 66-74, 2005.

[19] P. I. Haigh and D. R. Urbach, "The treatment and prognosis of Hürthle cell follicular thyroid carcinoma compared with its non-Hürthle cell counterpart," Surgery, vol. 138, no. 6, pp. 1152-1158, 2005.

[20] S. A. Hundahl, B. Cady, M. P. Cunningham et al., "Initial results from a prospective cohort study of 5583 cases of thyroid carcinoma treated in the united states during 1996. U.S. and German Thyroid Cancer Study Group. An American College of Surgeons Commission on Cancer Patient Care Evaluation study," Cancer, vol. 89, no. 1, pp. 202-217, 2000.

[21] Y. Nikiforov, P. W. Biddinger, and L. D. R. Thompson, Diagnostic Pathology and Molecular Genetics of the Thyroid, Wolters Kluwer Health/Lippincott Williams \& Wilkins, Philadelphia, 2012.

[22] R. A. DeLellis and C. International Agency for Research on, O. World Health, and P. International Academy of, Pathology and Genetics of Tumours of Endocrine Organs, IARC Press, Lyon, 2004.

[23] K. Sugino, K. Kameyama, K. Ito et al., "Does Hürthle cell carcinoma of the thyroid have a poorer prognosis than ordinary follicular thyroid carcinoma?," Annals of Surgical Oncology, vol. 20, no. 9, pp. 2944-2950, 2013.

[24] N. Besic, M. Hocevar, J. Zgajnar, R. Petric, and G. Pilko, "Aggressiveness of therapy and prognosis of patients with Hurthle cell papillary thyroid carcinoma," Thyroid, vol. 16, no. 1, pp. 67-72, 2006.

[25] A. M. Chindris, J. D. Casler, V. J. Bernet et al., "Clinical and molecular features of Hurthle cell carcinoma of the thyroid," The Journal of Clinical Endocrinology and Metabolism, vol. 100, no. 1, pp. 55-62, 2015.

[26] L. R. Henry, H. O. Lee, J. S. Lee et al., "Clinical implications of fibroblast activation protein in patients with colon cancer," Clinical Cancer Research, vol. 13, no. 6, pp. 17361741, 2007.

[27] J. Lee, S. Ham, M. H. Lee et al., "Dysregulation of Parkinmediated mitophagy in thyroid Hurthle cell tumors," Carcinogenesis, vol. 36, no. 11, pp. 1407-1418, 2015.

[28] K. T. Montone, Z. W. Baloch, and V. A. LiVolsi, “The thyroid Hurthle (oncocytic) cell and its associated pathologic conditions: a surgical pathology and cytopathology review," Archives of Pathology \& Laboratory Medicine, vol. 132, no. 8, pp. 1241-1250, 2008.

[29] J. Lee, S. Yi, Y. E. Kang et al., "Defective ciliogenesis in thyroid hurthle cell tumors is associated with increased autophagy," Oncotarget, vol. 7, no. 48, pp. 79117-79130, 2016.

[30] Y. Hu, X. Li, W. Xue et al., “TP53INP2-related basal autophagy is involved in the growth and malignant progression in human liposarcoma cells," Biomedicine \& Pharmacotherapy, vol. 88, pp. 562-568, 2017.

[31] D. H. Wu, C. C. Jia, J. Chen et al., “Autophagic LC3B overexpression correlates with malignant progression and predicts a poor prognosis in hepatocellular carcinoma," Tumour Biology, vol. 35, no. 12, pp. 12225-12233, 2014.

[32] R. K. Amaravadi, D. Yu, J. J. Lum et al., “Autophagy inhibition enhances therapy-induced apoptosis in a Myc-induced model of lymphoma," The Journal of Clinical Investigation, vol. 117, no. 2, pp. 326-336, 2007.

[33] J. S. Carew, E. C. Medina, J. A. Esquivel 2nd et al., “Autophagy inhibition enhances vorinostat-induced apoptosis via ubiquitinated protein accumulation," Journal of Cellular and Molecular Medicine, vol. 14, no. 10, pp. 2448-2459, 2010.

[34] J. S. Carew, S. T. Nawrocki, C. N. Kahue et al., "Targeting autophagy augments the anticancer activity of the histone deacetylase inhibitor SAHA to overcome Bcr-Abl-mediated drug resistance," Blood, vol. 110, no. 1, pp. 313-322, 2007.

[35] A. Gupta, S. Roy, A. J. Lazar et al., "Autophagy inhibition and antimalarials promote cell death in gastrointestinal stromal tumor (GIST)," Proceedings of the National Academy of Sciences of the United States of America, vol. 107, no. 32, pp. 14333-14338, 2010. 


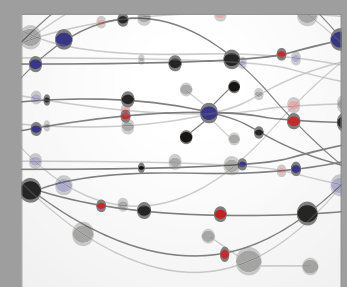

The Scientific World Journal
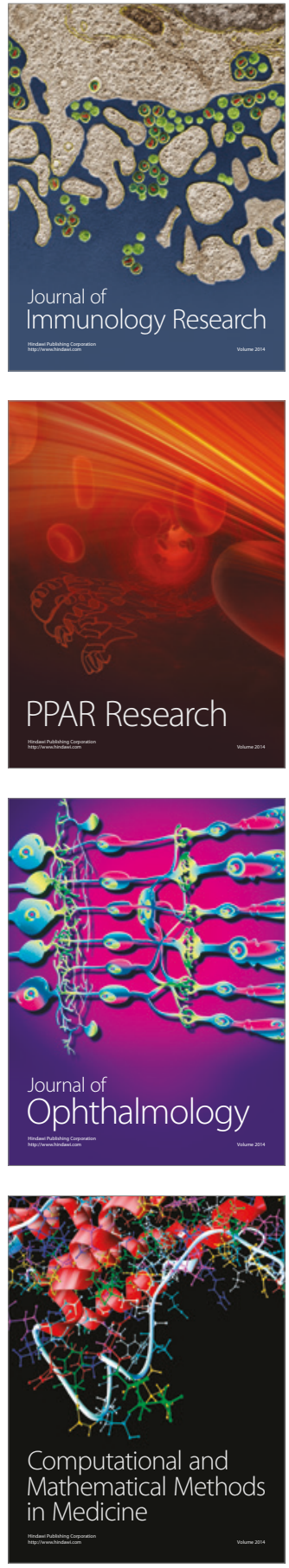

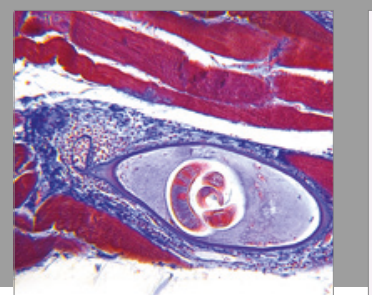

Gastroenterology Research and Practice
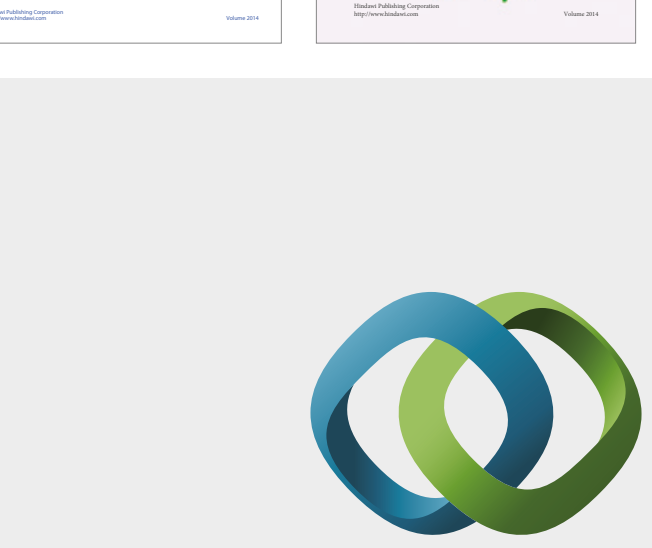

\section{Hindawi}

Submit your manuscripts at

https://www.hindawi.com
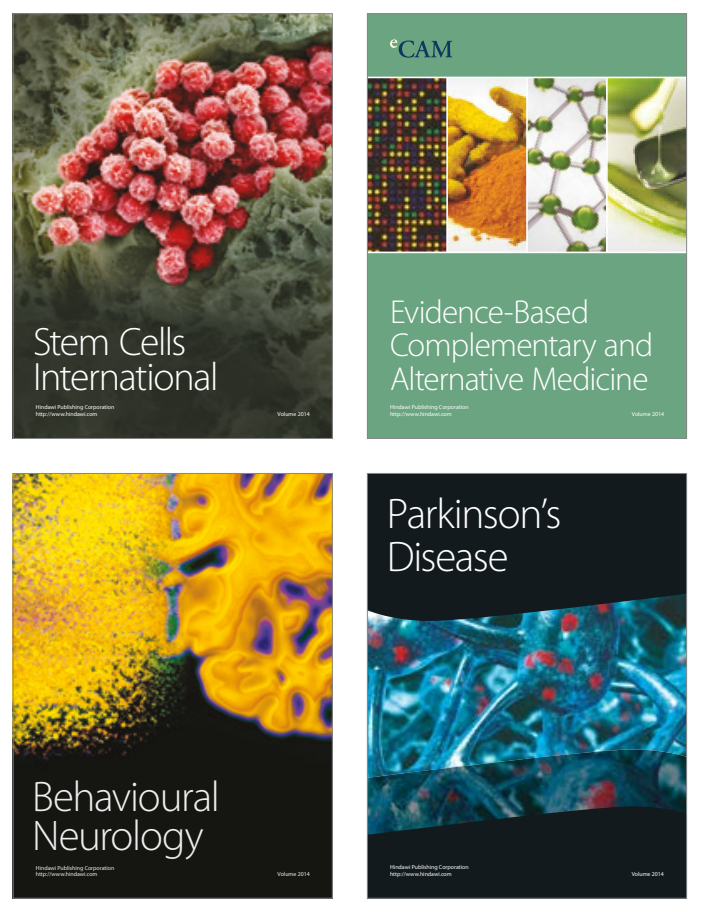
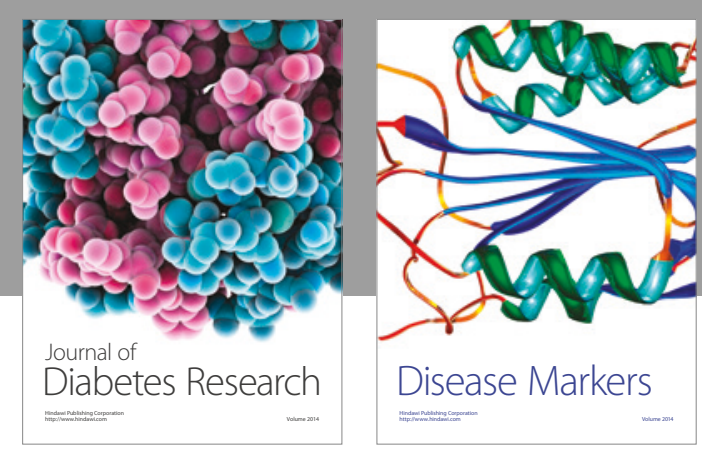

Disease Markers
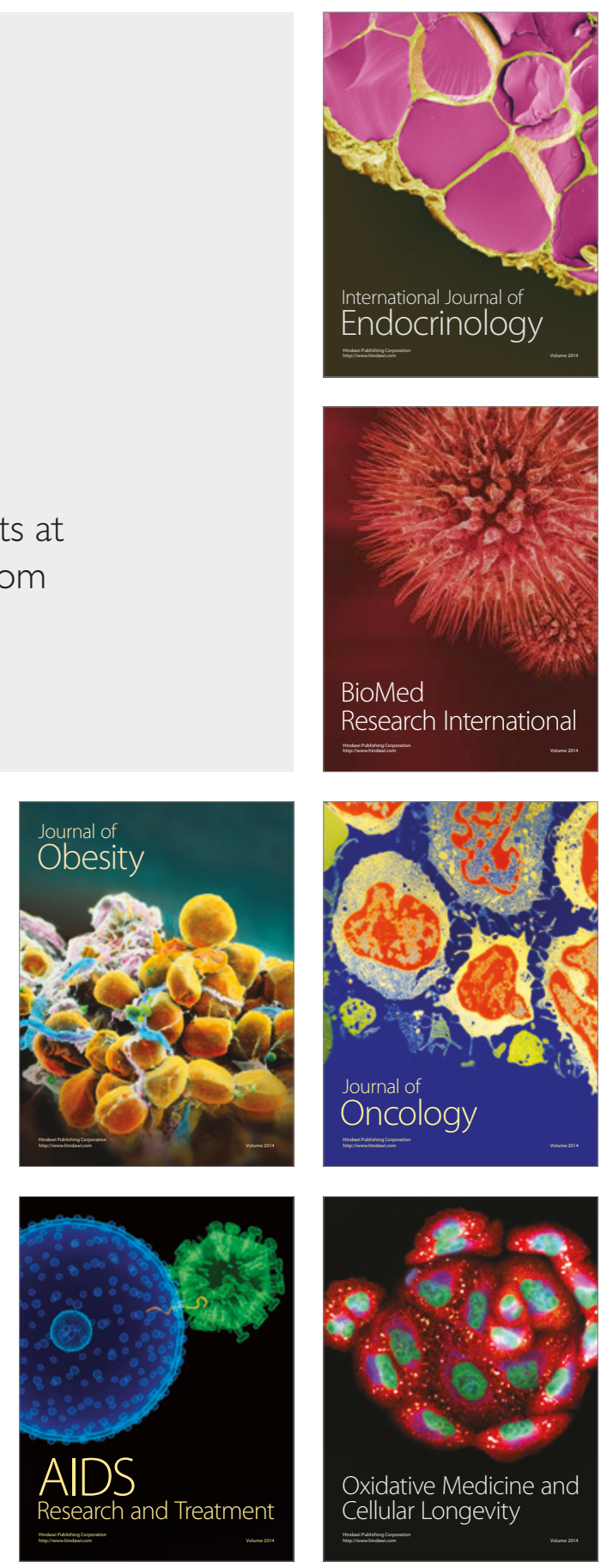